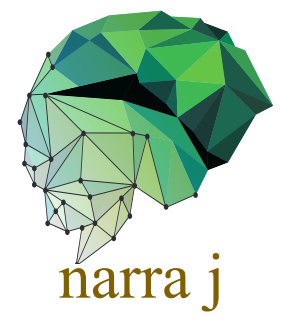

Original Article

\title{
Global prevalence of persistent neuromuscular symptoms and the possible pathomechanisms in COVID-19 recovered individuals: A systematic review and meta- analysis
}

\begin{abstract}
Jonny K. Fajar', Muhammad Ilmawan², Sukamto S. Mamada3, Endang Mutiawati4,5, Milda Husnah6, Hanifah Yusuf7, Firzan Nainu3, Salin Sirinam, Synat Keam9, Youdiil Ophinni'10,11, Francesco Rosiello' ${ }^{12}$, Marhami Fahriani13*and Sandro G.V. Rosa $\mathbf{1 4 , 1 5}^{14}$

${ }^{1}$ Brawijaya Internal Medicine Research Center, Department of Internal Medicine, Faculty of Medicine, Universitas Brawijaya, Malang, Indonesia; 2 Faculty of Medicine, Universitas Brawijaya, Malang, Indonesia; 3 Faculty of Pharmacy, Hasanuddin University, Tamalanrea, Makassar, Indonesia; 4Department of Neurology, School of Medicine, Universitas Syiah Kuala, Banda Aceh, Indonesia; 5Department of Neurology, Dr. Zainoel Abidin Hospital, Banda Aceh, Indonesia; ${ }_{6}$ Department of Biology, Faculty of Mathematics and Natural Sciences, Universitas Syiah Kuala, Banda Aceh, Indonesia; 7Department of Pharmacology, Faculty of Medicine, Universitas Syiah Kuala, Banda Aceh, Indonesia, ${ }^{8}$ Department of Tropical Pediatrics, Faculty of Tropical Medicine, Mahidol University, Bangkok, Thailand; 9School of Medicine, University of Western Australia, Perth, Western Australia, Australia; ${ }^{10}$ Ragon Institute of MGH, MIT and Harvard, Harvard Medical School, Harvard University, Cambridge, MA, USA; ${ }^{11}$ Immunology Frontier Research Center, Osaka University, Osaka, Japan; ${ }^{12}$ Department of Public Health and Infectious Disease, Sapienza-University of Rome, Rome, Italy; ${ }^{13}$ Medical Research Unit, School of Medicine, Universitas Syiah Kuala, Banda Aceh, Indonesia; ${ }^{14 D i r e t o r i a ~ d e ~}$ Patentes, Divisão De Farmácia - Instituto Nacional Da Propriedade Industrial, Rio de Janeiro, Brasil; ${ }^{15}$ Programa De Pós-Graduação Em Ciências Aplicadas a Produtos Para Saúde, Faculdade De Farmácia, Universidade Federal Fluminense, Brasil
\end{abstract}

*marhamifahriani@gmail.com

\section{Abstract}

This study was conducted to determine the prevalence of prolonged neuromuscular symptoms, including fatigue, anosmia, headache, myalgia, and joint pain in COVID-19 survivors hospitalized with mild, moderate, or severe infections worldwide. The search was conducted up to January 3oth, 2021 using three databases (PubMed, Scopus, and Web of Science) to identify potentially eligible studies. Data on study characteristics, follow-up characteristics, and severity of COVID-19 during hospitalization were collected in accordance with PRISMA guidelines. The Newcastle-Ottawa scale was used to assess the quality of relevant articles. The estimated prevalence of specific prolonged neuromuscular symptoms and the association between COVID-19 severity and occurrence of prolonged neuromuscular symptoms was analyzed wherever appropriate. Database search yielded 4,050 articles and 22 articles were included for meta-analysis. The estimated prevalence of prolonged fatigue was recorded in 21.2\% (95\%CI: $11.9 \%-$ $34.8 \%$ ) of 3,730 COVID-19 survivors. Persistent anosmia was recorded in 239 of 2,600 COVID-19 survivors (9.7\%, 95\%CI: 6.1\%-15.2\%). In 84 out of 2,412 COVID-19 survivors (8.9\%, 95\%CI: $3.2 \%-22.6 \%)$, prolonged headache was observed. A total of 53 out of 1,125 COVID-19 patients (5.6\%, 95\%CI: 2.1\%-14.2\%) complained of persistent myalgia even after being discharged from the hospital. The prevalence of prolonged joint pain was in $15.4 \%$ (95\%CI: $8.2 \%-27.2 \%$ ) of subjects. Due to data scarcity on COVID-19 severity and prolonged neuromuscular symptoms, association analysis could not be conducted. Widespread concern regarding long-term impacts of COVID-19 was raised 
after several studies reported prolonged symptoms in COVID-19 survivors. Numerous theories have been proposed to address this concern; however, as the research on this pandemic is still ongoing, no explanation is definitive yet. Therefore, follow-up studies in COVID-19 survivors after recovery from COVID-19 are warranted to determine the pathogenesis of prolonged symptoms. PROSPERO registration: CRD42021242332.

Keywords: COVID-19, prolonged symptom, long-term effect, neuromuscular, systematic review

\section{Introduction}

The pathophysiological extent of coronavirus disease 2019 (COVID-19) infection is yet to be assessed [1]. COVID-19, caused by the severe acute respiratory syndrome coronavirus 2 (SARSCoV-2), was declared as a global pandemic on March 11, 2020. After more than a year, the end of COVID-19 pandemic is still uncertain although several 'return to normal' theories have been discussed since the beginning of the global COVID-19 vaccination program [2-4]. Not only the healthcare system $[5-8]$ but the global economy and education $[9,10]$ have also been hit equally hard [11-13], particularly by the lockdown policies [9, 14]. Although numerous proposed treatments have been investigated [15-19] many failed to provide good efficacy to treat severe COVID-19.

SARS-CoV-2 infection mainly attacks the respiratory system. Involvement of other organs has also been reported [20-24]. Studies assessing the effects of COVID-19 on the cardiovascular system [25, 26], liver [27], and the central nervous system [28, 29] have been conducted. The prevalence of anosmia and dysgeusia [30], hemorrhagic and ischemic stroke [31], and gastrointestinal symptoms in COVID-19 patients have also been previously studied [32]. Currently, concerns about the persistence of COVID-19 symptoms even after recovery have been raised in several articles, particularly in the context of neurological manifestation such as fatigue [33, 34], headache [35], and anosmia [36]. Although no direct association of prolonged fatigue with laboratory markers and COVID-19 severity has been reported [33], persistent fatigue was the most common symptom experienced by 80\% of COVID-19 patients even after six months of recovery [37]. Moreover, varying degrees of depression, sleep difficulties, and anxiety among healthcare workers post COVID-19 infection were published so far [38, 39].

The need for continuous monitoring of all COVID-19 cases irrespective of the clinical severity of the initial acute infection has been raised, particularly after prolonged symptoms such as dizziness, muscle pain, headache, fatigue, and anosmia were reported among asymptomatic or mildly symptomatic patients for months [40]. This systematic review was conducted to address (a) the global estimated prevalence of prolonged neuromuscular symptoms (fatigue, anosmia, headache, myalgia, and joint pain) in recovered COVID-19 patients and (b) the association of COVID-19 severity with prolonged neuromuscular symptoms.

\section{Methods}

\section{Registration and protocol}

The study followed the Preferred Reporting Items for Systematic Reviews and Meta-analyses (PRISMA) guidelines for searching databases and reporting our findings [41], as presented in Supplementary Material. In addition, the study protocol was registered on PROSPERO registration (CRD42021242332) and no ethical approval was required. Partial results of this systematic review have been published elsewhere [39].

\section{Eligibility criteria of studies}

The inclusion criteria were articles reporting at least one persistent neuromuscular symptom (fatigue, anosmia, headache, myalgia, and joint pain) in recovered COVID-19 hospitalized patients. All studies must have included real-time polymerase chain reaction (RT-PCR) results of SARS-COV-2 RNA from nasal or oropharyngeal swab samples for confirmation of COVID-19. 
Recovered patients were defined as all COVID-19 patients who met the discharge criteria from the WHO or China National Health Commission [42, 43]. Data for prolonged neuromuscular symptoms was collected only in recovered patients with persistent symptoms for at least two weeks after discharge.

The exclusion criteria included editorials, commentaries, reviews, case reports, and case series. In addition, cases, where the diagnosis of COVID-19 was confirmed based on only radiology or symptoms were excluded. Finally, only articles written in English and published between 2019 to 2021 were included in this study.

\section{Information sources and search strategy}

The search was performed in three databases (PubMed, Scopus, and Web of Science) as of January 30, 2021 to identify potential studies. The keywords used were ("SARS-CoV-2" OR "COVID-19" OR "Wuhan coronavirus" OR "Wuhan virus" OR "novel coronavirus" OR "nCoV" OR "severe acute respiratory syndrome coronavirus 2" OR "coronavirus disease 2019" OR "2019-nCoV" OR "2019 novel coronavirus" OR "SARS 2") AND ("prolong*" OR "follow-up" OR "persistent" OR "sequelae" OR "consequen*" OR "prospective" OR "cohort" OR "long-term" OR "follow*" OR "longitudinal"). The details of the search strategy for each database have been published elsewhere [39].

\section{Study selection and data extraction}

Endnote X9 (Thompson Reuters, Philadelphia, PA, USA) was used as a reference manager where all studies were imported and duplicates were removed. The first screening was done on titles and abstracts of all references to identify eligible articles. The second screening was conducted on the full texts of potentially eligible studies and decided the eligibility of each study based on the inclusion criteria and the availability of the data. Data extraction included data from main articles and supplementary materials, whenever required. In addition, a list of references was also retrieved as explained in previous studies [30, 31, 44] to explore additional studies. The extracted data included study characteristics of eligible studies (author(s), publication year, location of the study, and study design) and follow-up characteristics (extent of follow-up conducted after discharge, number of COVID-19 patients, number of COVID-19 patients with prolonged neuromuscular symptoms, and severity of COVID-19 infection during admission to the hospital).

\section{Outcomes}

The two main outcomes of this study were as follows: (a) global prevalence of persistent neuromuscular symptoms: fatigue, anosmia, headache, myalgia, and joint pain and (b) association of COVID-19 severity with the presence of persistent neuromuscular symptoms (fatigue, anosmia, headache, myalgia, and joint pain).

\section{Data synthesis}

The prevalence of each persistent neuromuscular symptom (fatigue, anosmia, headache, myalgia, and joint pain) was calculated as the number of patients with a prolonged symptom divided by the total number of patients with COVID-19 with or without the specific neuromuscular symptom during the follow-up and expressed as frequency (\%) with a 95\% confidence interval (CI). The association of COVID-19 severity with risk of prolonged neuromuscular symptoms was also calculated using z-test and presented as odds ratio and 95\% confidence interval $(95 \% \mathrm{CI})$. Forest plots were used to visualize the data.

\section{Risk of bias assessment}

The quality appraisal of eligible studies was performed using the Newcastle-Ottawa scale (NOS) [45]. Nine characteristics of a study including four items for sample collection, one item for group comparison, and three items for the outcome was considered in NOS with the score range of o to 9. A high-quality article was defined as a study with a NOS score $\geq 7$, while moderate and low-quality articles were studies with NOS scores between $5^{-6}$ and $\leq 4$, respectively. 


\section{Statistical analysis}

Data analysis was performed on Review Manager version 5.3 [46]. Heterogeneity of the pooled data was evaluated using the Q test and I2 statistic. Data were analyzed using a random-effect or fixed-effect model as appropriate. Publication bias was assessed using Egger's test, with $\mathrm{p}<0.05$ considered as potentially having publication bias.

\section{Results}

\section{Study eligibility results}

Database search resulted in 4,050 articles, of which 2,045 publications were duplicates. The remaining 2,005 studies underwent first screening on titles and abstracts, yielding 761 potentially eligible studies (Figure 1). The second screening excluded an additional 739 articles which did not meet the inclusion criteria. The final result included 22 articles for meta-analysis.

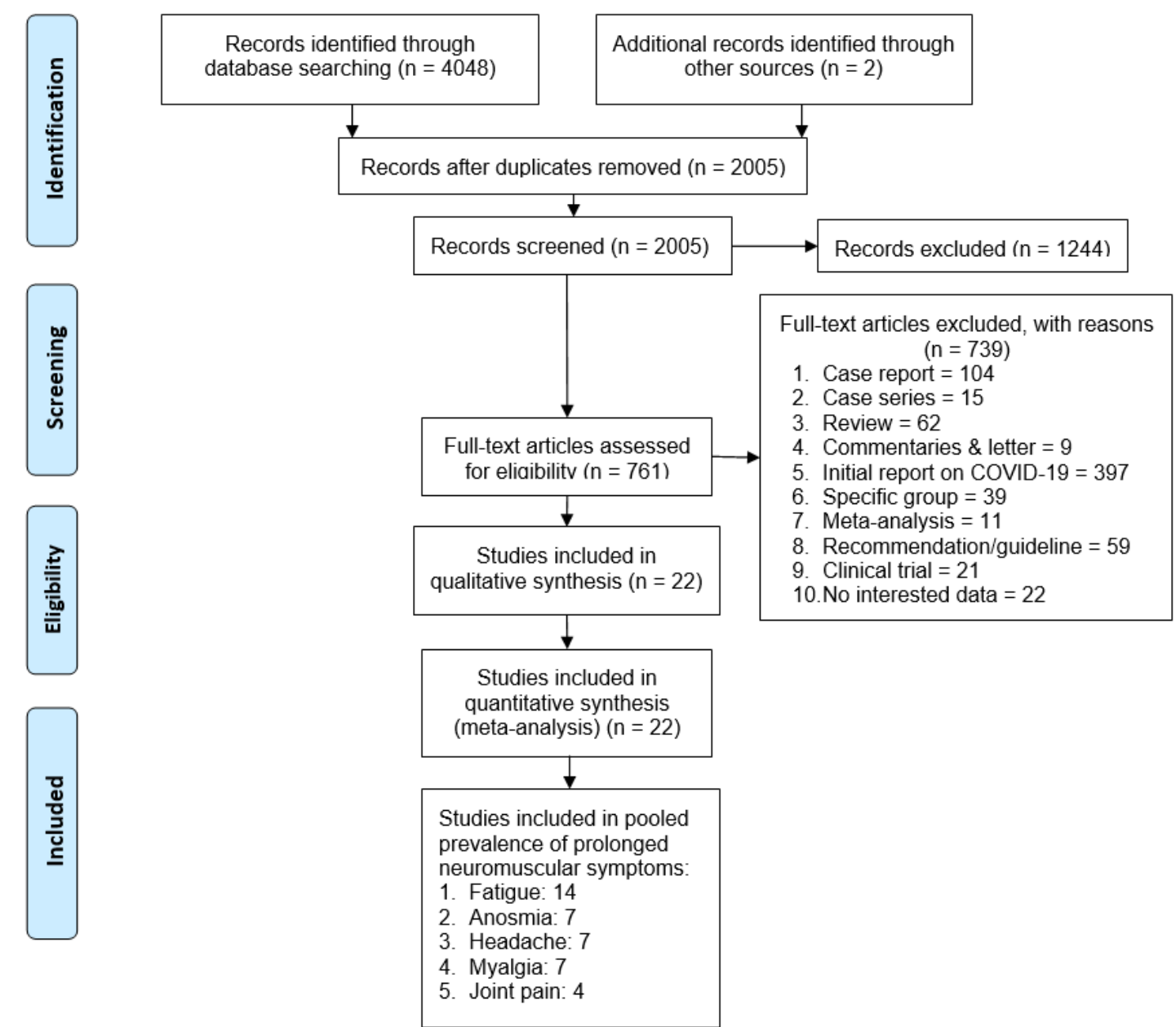

Figure 1. Flowchart of literature search according to PRISMA

The prevalence of persistent neuromuscular symptoms was calculated from 14 studies for fatigue [33, 47-59], 7 studies for anosmia [48-50, 52-54, 60], 7 studies for headache [48-50, 52, $54,55,57]$ and myalgia $[48-50,52,55,56,58]$, and 4 studies for joint pain $[47,48,50,58]$. The studies included for the meta-analysis of prevalence of prolonged neuromuscular symptoms are summarized in Table 1.

The information of COVID-19 severity on admission and the occurrence of prolonged neuromuscular symptoms were scarce. Therefore, no additional analysis could be performed. 
Table 1. The prevalence of prolonged neuromuscular symptoms among COVID-19 survivors

\begin{tabular}{|c|c|c|c|c|c|c|c|c|c|c|}
\hline \multirow[t]{2}{*}{ Symptoms } & \multirow[t]{2}{*}{ Year } & \multirow[t]{2}{*}{ Study design } & \multirow[t]{2}{*}{ City } & \multirow[t]{2}{*}{ Country } & \multirow{2}{*}{$\begin{array}{l}\text { Day from discharge to } \\
\text { follow-up } \\
\text { Day }( \pm \mathrm{SD}) \text { or Day (min- } \\
\text { max) }\end{array}$} & \multicolumn{3}{|c|}{$\begin{array}{l}\text { Prevalence of prolonged neuromuscular } \\
\text { symptoms over total followed COVID-19 } \\
\text { survivors }\end{array}$} & \multirow[t]{2}{*}{ NOS } & \multirow[t]{2}{*}{ Reference } \\
\hline & & & & & & No patients & Total patients & Percentage & & \\
\hline \multirow[t]{15}{*}{ Fatigue } & 2020 & Prospective & Wuhan & China & 14 & 7 & 131 & $5 \cdot 3$ & 7 & {$[55]$} \\
\hline & 2020 & Prospective & Isfahan & Iran & $72(62-87)$ & 50 & 452 & 11.1 & 9 & [54] \\
\hline & 2021 & Cohort & Hubei & China & $153(146-160)$ & 1038 & 1655 & 62.7 & 8 & {$[50]$} \\
\hline & 2020 & prospective & Fuyang & China & 90 & 4 & 60 & 6.7 & 7 & [52] \\
\hline & 2020 & Cohort & Georgia & USA & $38(21-49)$ & 17 & 26 & 65.4 & 8 & [48] \\
\hline & 2021 & Prospective & Wuhan & China & $97(95-102)$ & 152 & 538 & 28.3 & 8 & [58] \\
\hline & 2020 & Prospective & Aachen & Germany & $56(48-71)$ & 15 & 33 & $45 \cdot 5$ & 8 & [49] \\
\hline & 2020 & Prospective & Henan & China & 90 & 9 & 55 & 16.4 & 7 & [57] \\
\hline & 2020 & Prospective & Wuhan & China & 14 & 5 & 337 & 1.5 & 7 & [56] \\
\hline & 2020 & Prospective & Dublin & Ireland & & 22 & 128 & 17.2 & 9 & [33] \\
\hline & 2020 & Prospective & Rome & Italy & $60.3( \pm 13.6)$ & 76 & 143 & 53.1 & 7 & {$[47]$} \\
\hline & 2020 & Prospective & Tokyo & Japan & $108( \pm 23)$ & 10 & 58 & 17.2 & 7 & [53] \\
\hline & 2020 & Prospective & Wuhan & China & 28 & 1 & 38 & 2.6 & 7 & [59] \\
\hline & 2020 & Prospective & Wuhan & China & 90 & 45 & 76 & 59.2 & 8 & {$[51]$} \\
\hline & Total & & & & & 1451 & 3730 & 38.9 & & \\
\hline \multirow[t]{8}{*}{ Anosmia } & 2020 & Prospective & Isfahan & Iran & 28 & 21 & 452 & 4.6 & 9 & [54] \\
\hline & 2021 & Cohort & Hubei & China & $153(146-160)$ & 176 & 1655 & 10.6 & 8 & [50] \\
\hline & 2020 & Prospective & Fuyang & China & 90 & 2 & 60 & $3 \cdot 3$ & 7 & {$[52]$} \\
\hline & 2020 & Cohort & Georgia & USA & $38(21-49)$ & 8 & 26 & 30.8 & 8 & [48] \\
\hline & 2020 & Prospective & Aachen & Germany & $56(48-71)$ & 4 & 33 & 12.1 & 8 & [49] \\
\hline & 2020 & Prospective & California & USA & $9.4(3.8-14.8)$ & 18 & 316 & $5 \cdot 7$ & 8 & [6o] \\
\hline & 2020 & Prospective & Tokyo & Japan & $108( \pm 23)$ & 10 & 58 & 17.2 & 7 & [53] \\
\hline & Total & & & & & 239 & 2600 & 9.2 & & \\
\hline \multirow[t]{5}{*}{ Headache } & 2020 & Prospective & Isfahan & Iran & 28 & 12 & 452 & 2.7 & 9 & [54] \\
\hline & 2020 & Prospective & Wuhan & China & 14 & 5 & 131 & 3.8 & 7 & [55] \\
\hline & 2021 & Cohort & Hubei & China & $153(146-160)$ & 33 & 1655 & 2.0 & 8 & {$[50]$} \\
\hline & 2020 & Prospective & Fuyang & China & 90 & 6 & 60 & 10.0 & 7 & {$[52]$} \\
\hline & 2020 & Cohort & Georgia & USA & $38(21-49)$ & 13 & 26 & 50.0 & 8 & [48] \\
\hline
\end{tabular}


Fajar et al. Narra J 2021; 1 (3): e48 - http://doi.org/10.52225/narra.vii3.48

\begin{tabular}{|c|c|c|c|c|c|c|c|c|c|c|}
\hline \multirow[t]{2}{*}{ Symptoms } & \multirow[t]{2}{*}{ Year } & \multirow[t]{2}{*}{ Study design } & \multirow[t]{2}{*}{ City } & \multirow[t]{2}{*}{ Country } & \multirow{2}{*}{$\begin{array}{l}\text { Day from discharge to } \\
\text { follow-up } \\
\text { Day ( } \pm \text { SD) or Day (min- } \\
\text { max) }\end{array}$} & \multicolumn{3}{|c|}{$\begin{array}{l}\text { Prevalence of prolonged neuromuscular } \\
\text { symptoms over total followed COVID-19 } \\
\text { survivors }\end{array}$} & \multirow[t]{2}{*}{ NOS } & \multirow[t]{2}{*}{ Reference } \\
\hline & & & & & & No patients & Total patients & Percentage & & \\
\hline \multirow{7}{*}{ Myalgia } & 2020 & Prospective & Aachen & Germany & $56(48-71)$ & 5 & 33 & 15.2 & 8 & [49] \\
\hline & 2020 & Prospective & Henan & China & 90 & 10 & 55 & 18.2 & 7 & [57] \\
\hline & Total & & & & & 84 & 2412 & 3.5 & & \\
\hline & 2021 & Cohort & Hubei & China & $153(146-160)$ & 39 & 1655 & 2.4 & 8 & {$[50]$} \\
\hline & 2020 & Prospective & Wuhan & China & 14 & 1 & 131 & 0.8 & 7 & {$[55]$} \\
\hline & 2020 & Prospective & Fuyang & China & 90 & 15 & 60 & 25.0 & 7 & {$[52]$} \\
\hline & 2020 & Cohort & Georgia & USA & $38(21-49)$ & 7 & 26 & 26.9 & 8 & [48] \\
\hline \multirow{9}{*}{ Joint pain } & 2021 & Prospective & Wuhan & China & $97(95-102)$ & 24 & 538 & 4.5 & 8 & [58] \\
\hline & 2020 & Prospective & Aachen & Germany & $56(48-71)$ & 5 & 33 & 15.2 & 8 & [49] \\
\hline & 2020 & Prospective & Wuhan & China & 14 & 1 & 337 & 0.3 & 7 & [56] \\
\hline & Total & & & & & 53 & 1125 & 4.7 & & \\
\hline & 2021 & Cohort & Hubei & China & $153(146-160)$ & 154 & 1655 & 9.3 & 8 & {$[50]$} \\
\hline & 2020 & Cohort & Georgia & USA & $38(21-49)$ & 8 & 26 & 30.8 & 8 & [48] \\
\hline & 2021 & Prospective & Wuhan & China & $97(95-102)$ & 41 & 538 & 7.6 & 8 & [58] \\
\hline & 2020 & Prospective & Rome & Italy & $60.3( \pm 13.6)$ & 39 & 143 & $27 \cdot 3$ & 7 & [47] \\
\hline & Total & & & & & 242 & 2362 & 10.2 & & \\
\hline
\end{tabular}

Min-max: minimum-maximum, NOS: Newcastle-Ottawa scale, SD: standard deviation 
Prevalence of prolonged neuromuscular symptoms in patients with COVID-19 Prolonged fatigue was recorded in 1,451 out of 3,730 recovered COVID-19 patients, with an estimated prevalence of 21.2\% (95\%CI: 11.9\%-34.8\%) (Figure 2). Persistent anosmia was reported in 239 out of 2,600 COVID-19 survivors, corresponding to a pooled prevalence of $9.7 \%$ (95\%CI: 6.1\%-15.2\%). Persistent headache was identified in seven studies that included 2,412 patients with COVID-19 out of which 84 patients were reported to have had the symptom, corresponding to an estimated prevalence of 8.9\% (95\%CI: 3.2\%-22.6\%) (Figure 3). Myalgia was reported in 53 out of 1,125 patients with COVID-19, with an estimated prevalence of $5.6 \%$ (95\%CI: $2.1 \%-14.2 \%$ ). The last four studies identified 242 cases of persistent joint pain out of a total of 2,362 COVID-19 survivors, which corresponds to an estimated prevalence of $15.4 \%$ (95\%CI: $8.2 \%-27.2 \%)$.

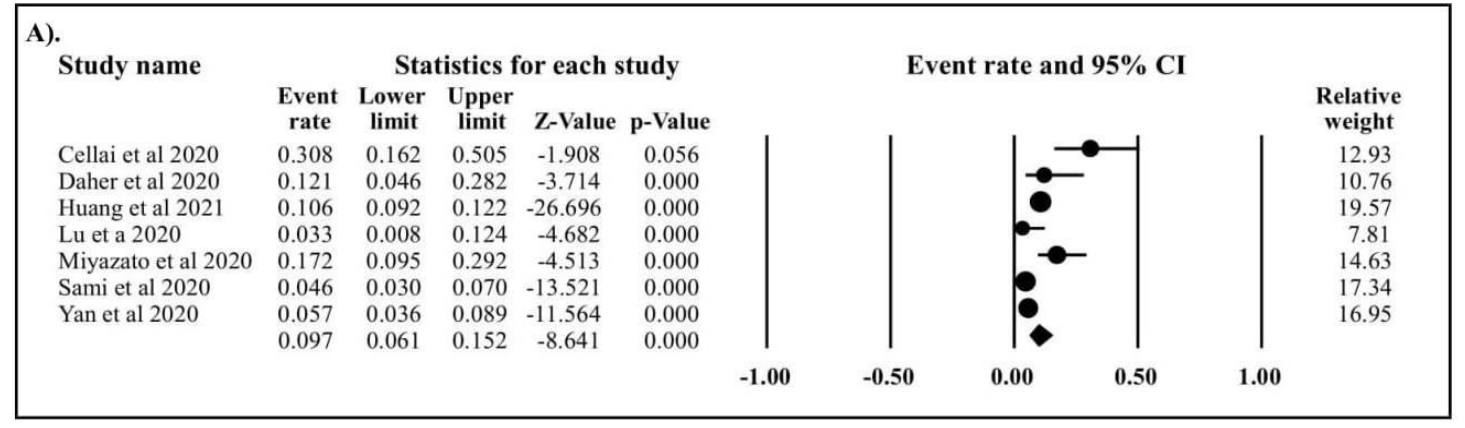

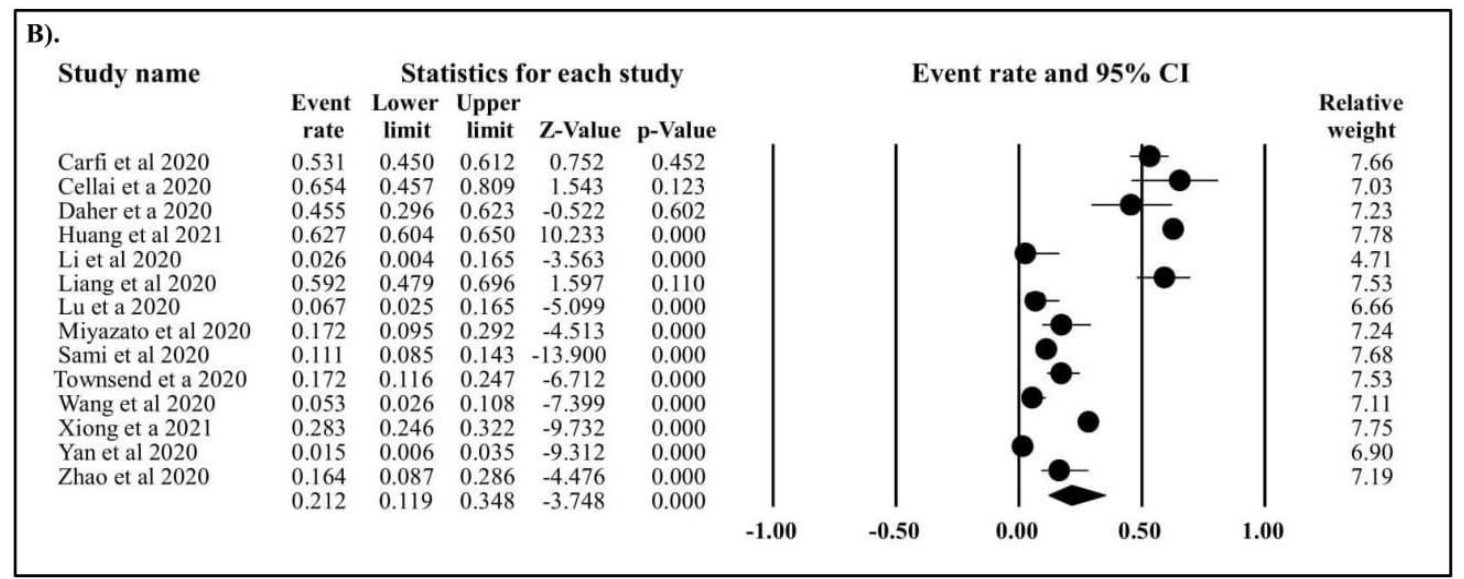

Figure 2. Forest plot of prolonged anosmia and fatigue in COVID-19 survivors. (A) Estimated prevalence of prolonged anosmia in COVID-19 survivor (event rate: $9.7 \%, 95 \% \mathrm{CI}$ : $6.1 \%-15.2 \%$, p<0.001, p Egger 0.577, p heterogeneity <0.0001. (B) Estimated prevalence of prolonged fatigue in COVID-19 survivor (event rate: 21.2\%, 95\%CI: 11.9\%-34.8\%, p<0.001, p Egger: 1.254, p heterogeneity $<0.0001$.

\section{Association of COVID-19 severity and prolonged neuromuscular symptoms}

The association of COVID-19 severity with persistent neuromuscular symptoms could not be analyzed due to insufficient data on prolonged neuromuscular symptoms in patients with mild to moderate and severe COVID-19.

\section{Discussion}

During the initial months of the pandemic, the primary focus of doctors and scientists worldwide was to improve the patient's condition, especially their respiratory and to help them overcome the disease mostly by repurposing drugs already in clinical use [61, 62]. The impact of COVID-19 on the respiratory system was well studied. However, its effects on the other organs were still limited. Around April, 2020, that the first studies reporting the effects of SARS-CoV-2 on the brain emerged [63]. Our study found that persistent neuromuscular symptoms were 
observed in COVID-19 survivors, such as fatigue (21.2\%), anosmia (9.7\%), headache (8.9\%), joint pain (15.4\%) and myalgia (5.6\%). These results are in line with CDC that declared that persistent fatigue and headache ( $71 \%$ and $61 \%$, respectively) as the most commonly reported prolonged neuromusculoskeletal symptoms of COVID-19 in the US [64]. One study reported inflammation in the brain tissues of a patient with meningoencephalitis associated with SARSCoV-2 infection [65]. Another report provided evidence of persistent central nervous system (CNS) complications in COVID-19 patients, which included encephalopathy [63], psychosis [66], and stroke [67]. Long-term complications were also observed in the peripheral nervous system, such as the Guillain-Barré syndrome (GBS) [68] and brachial plexus neuropathy [6971]. Recent studies have reported new-onset of myasthenia gravis (MG) in COVID-19 survivors without previous history of neurological and autoimmune disorders following recovery of initial infection [72], suggesting that COVID-19 can trigger autoimmune disease. Several reports on musculoskeletal manifestations of COVID-19 have also emerged with myalgia as the most commonly reported symptom [73-75].
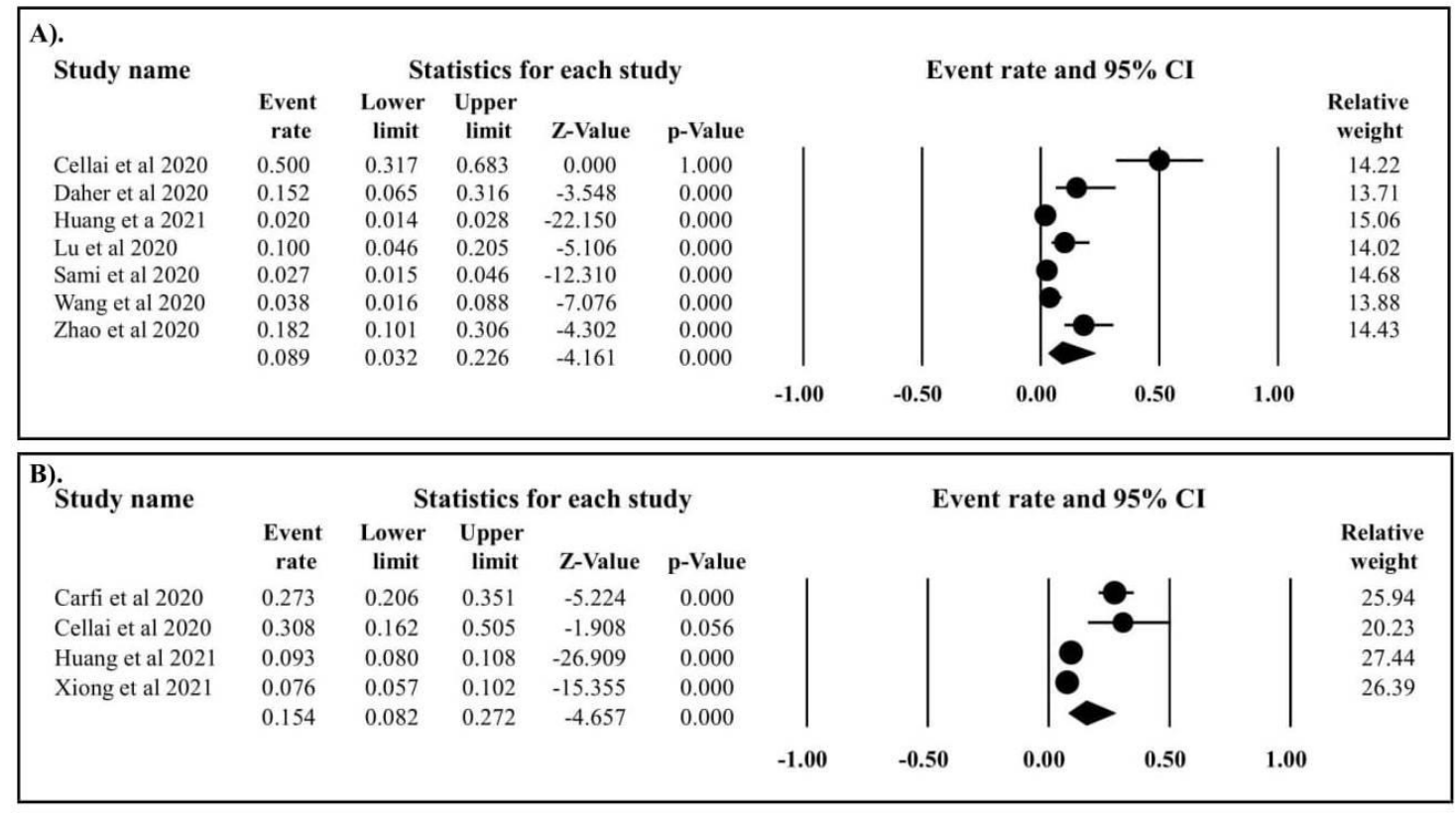

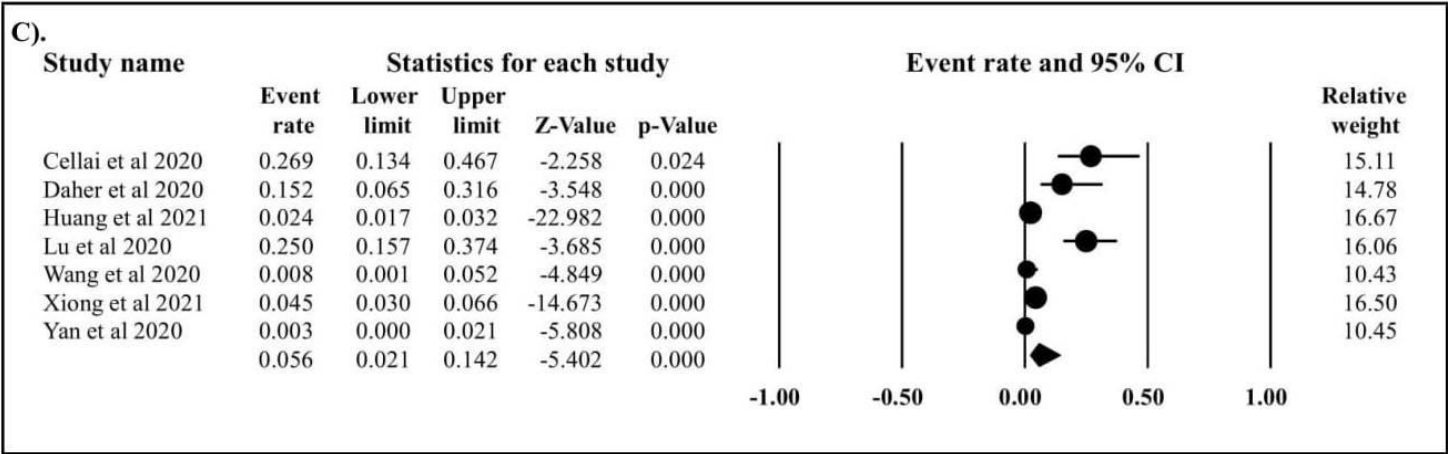

Figure 3. Forest plot of symptoms in COVID-19 survivors. (A) Estimated prevalence of prolonged headache in COVID-19 survivor (event rate: 8.9\%, 95\%CI: $3.2 \%-22.6 \%, \mathrm{p}<0.001, \mathrm{p}$ Egger 1.429, p heterogeneity <0.0001. (B) Estimated prevalence of prolonged joint pain in COVID-19 survivor (event rate: 15.4\%, 95\%CI: 8.2\%-27.2\%, p<0.001, p Egger 0.692, p heterogeneity <0.0001. (C) Estimated prevalence of prolonged myalgia in COVID-19 survivor (event rate: 5.6\%, 95\%CI: 2.1\%-14.2\%, p<0.001, p Egger 1.270, p heterogeneity <0.0001.

\section{Possible pathomechanisms of neuromuscular manifestations}

With evidence of prolonged neuromuscular manifestations of COVID-19 infection rapidly accumulating, COVID-19 has now been acknowledged as a threat to the nervous system as well [76]. Questions such as "Who are at risk of developing neuromuscular complications?", "Why do 
these symptoms appear?", and "Are these symptoms are a lifelong consequence of COVID-19?" remain to be elucidated. Although theories of direct viral infection to the CNS, post-infection immune-mediated processes, and viral infection-induced hyperinflammation and hypercoagulability have been discussed, a definitive explanation for the pathogenesis of neuromusculoskeletal involvement is still due [76]. The elucidation of the molecular mechanisms underlying these symptoms is critical for the further development of treatment strategies. Moreover, the scenario for each of the different symptoms might be different or even contradictory. Olfactory cleft opacification and olfactory nerve inflammation have been observed, suggesting direct entry of the virus into the CNS from the olfactory bulb [77] and, therefore, direct brain infection of SARS-CoV-2 which requires antiviral therapy. A study using 'organoid', a miniature brain tissue model, has shown that SARS-CoV-2 can directly infect and kill neural cells [78]. Supporting this finding, another study that used mice expressing human ACE2 under the K18 promoter (K18-hACE2) reported neurotropism of SARS-CoV-2 [79]. However, another study in COVID-19 patients with peripheral nervous system involvement, such as acute inflammatory demyelinating polyradiculoneuropathy, reported elevated proinflammatory cytokines IL-6 and IL-8, indicating viral infection-induced hyperinflammatory response [8o] which would require anti-inflammatory therapy. Therefore, knowledge of pathogenesis is crucial as administering anti-inflammatory drugs to patients with brain infection might lead to a contradictory and fatal outcome [81, 82].

Several studies have reported the presence of SARS-CoV-2 in the CNS [83, 84] indicating a neurotropic tendency of the virus. This is further supported by a study which showing that neurons and glial cells widely express ACE2 [85], thereby facilitating the entry of the SARS$\mathrm{CoV}-2$ virus into the cell. Following CNS infection, several neurological symptoms emerge. Among various vulnerable targets, the neuromuscular network is one such target to be attacked by the virus. Impairment of the neuromuscular network ultimately leads to the emergence of neuromuscular symptoms such as fatigue, anosmia, muscle weakness, headache, myalgia, and joint pain [86]. The presence of neuromuscular symptoms indicates damage to either the motor nerves controlling voluntary muscular functions (such as in neuromuscular junction leading to disturbances in neuromuscular transmission) or the sensory nerves [87].

It has been found that excessive production of proinflammatory cytokines has pathological roles in the development of some neuromuscular disorders. For example, deposition of intraneuronal $\alpha$-synuclein and transactive DNA binding protein-43 (TDP-43) in Parkinson's disease and amyotrophic lateral sclerosis, respectively, is sensed by microglia leading to subsequent activation of $\mathrm{NF}-\mathrm{\kappa B}$ and $\mathrm{AP}-1$ signaling pathways [88]. Activating signaling pathways culminates in the production of several pro-inflammatory cytokines (e.g., TNF- $\alpha$ and IL-1 $\beta$ ) that attack dopaminergic neurons in PD and motor neurons in amyotrophic lateral sclerosis, leading to the emergence of some motoric disturbances, such as rigidity, tremor, and bradykinesia [88].

According to the aforementioned cases, several neuromuscular symptoms displayed by COVID-19 patients could also be associated with the overproduction of proinflammatory cytokines. This hypothesis is particularly convincing as 'cytokine storm' has been reported in many COVID-19 patients [89]. Headache, for example, has been linked to high levels of proinflammatory cytokines. Specifically, this symptom is caused by the activation of the trigeminovascular system which leads to excessive production of some neuropeptides, such as calcitonin gene-related peptide (CGRP), substance $\mathrm{P}$, and pituitary adenylate cyclase-activating polypeptide (PACAP) [90]. Although several mechanisms are involved in the activation of the trigeminovascular system and release of neuropeptides, proinflammatory cytokines, especially IL-1, IL-6, and TNF- $\alpha$, are strongly suspected of playing an important role in these mechanisms $[91,92]$.

Some possible pathogenesis of anosmia seen in COVID-19 patients has been described elsewhere [93]. Impairment in either peripheral olfactory nerves or the olfactory center in the brain is suspected as the primary contributing factors in the pathogenesis of anosmia [94]. However, damage to the olfactory supporting cells called sustentacular cells has been attracting bigger interest because these cells express higher levels of ACE2 and TMPRSS than the other 
cells involved in olfactory processes and are also located near the external environment [95, 96]. Nonetheless, dysfunctionalities in either olfactory nerves or olfactory supporting cells are closely related to the action of proinflammatory cytokines. TNF- $\alpha$ and IL-6 seem to be the major cytokines involved in the impairment of olfactory-related cells, both in peripheral and central nervous systems [97].

COVID-19-related neuromuscular symptoms could also be due to hypoxic conditions. However, in the end, it is the inflammation and oxidative stress caused as a result of hypoxia that underlies the emergence of these symptoms. Damage to the respiratory system during the course of COVID-19 leads to decreased oxygen supply in the body [98]. The insufficient oxygen levels eventually disturb energy production in many cells, including neuronal cells innervating the muscle cells. In hypoxic conditions, cells will produce energy by the anaerobic mechanism resulting in excessive by-products generation, including succinate and lactate [99-101]. The accumulation of these metabolites, particularly lactate, is attributed to fatigue conditions [102].

Furthermore, these by-products can promote the secretion of proinflammatory mediators, such as cytokines and reactive oxygen species (ROS). Succinate activates macrophages causing them to release IL-1 $\beta$ [103]. A study found that increased levels of lactic acid secreted by tumor cells activate the IL-23/IL-17 proinflammatory pathway [104]. In contrast, another study confirmed that lactate production played an important role in initiating IL-6 release [105]. Therefore, the presence of these metabolites from anaerobic mechanism of energy production could aggravate fatigue conditions in COVID-19 patients.

Indeed, the expression levels of all biomarkers related to fatigue have been detected to be out of the normal range in COVID-19 patients. Lactate level, as one of the adenosine triphosphates (ATP) metabolism biomarkers, has been reported to be elevated by some studies $[89,106,107]$. The levels of the other fatigue biomarkers have also been reported to be imbalanced in COVID-19 patients, for example, oxidative stress biomarkers (elevated level of ROS and reduced level of antioxidants) and inflammation biomarkers (increased levels of proinflammatory cytokines such as IL-6 and TNF- $\alpha$ ) [107-109].

Furthermore, oxygen deficiency activates transcriptional factors called hypoxia-inducible factors (HIFs), including HIF-1 $\alpha$ [110]. Following HIF-1 $\alpha$ activation, the expression of genes responsible for physiological processes such as angiogenesis, erythropoiesis, cell proliferation as well as inflammation is upregulated under oxygen-deprived conditions [111].

In addition to oxygen-dependent activation, HIF-1a activation is also induced by proinflammatory cytokines, growth factors, and exogenous toxins [111]. Interestingly, this induction can take place even under normal oxygen levels according to some studies that have reported that TNF- $\alpha$ and IL- $1 \beta$ promoted the expression and activity of HIF-1 $\alpha$ via NF- $\kappa B$ signaling pathway in cells even in the presence of sufficient oxygen supply [112-114].

COVID-19-induced hypoxia could lead to the overproduction of oxygen free radicals resulting in increased oxidative stress. Several studies have demonstrated that oxidative stress is positively correlated with incidents of neuromuscular symptoms such as fatigue, myalgia, and joint pain $[101,115,116]$. The excessive production of ROS could be caused by disturbances in the electron transport chain in mitochondria, various enzymatic systems (e.g., NADPH oxidase, xanthine oxidase, and nitric oxide synthase), or endoplasmic reticulum [101] as oxygen supply to these systems are diminished in hypoxic conditions. As a result, this can lead to the oxidation of lipids, proteins, and DNA followed by the triggering of inflammatory events. Intriguingly, oxidative stress and inflammatory cells have a reciprocal correlation. The excessive production of ROS promotes inflammation, and inflammatory cells also enhance the release of ROS at sites of inflammation [101].

\section{Conclusion}

The prolonged neuromuscular symptoms are concerning as the estimated prevalence of these symptoms is still high even after two weeks of recovery. Although proposed molecular mechanisms underlying the pathophysiology are yet to be addressed, this study adds new insights to the long-term impact of COVID-19 in recovered patients. How COVID-19 affects the 
quality of life in recovered patients is necessary to be determined in global follow-up cohort studies.

\section{Ethics approval}

Not required.

\section{Acknowledgments}

Authors would like to Universitas Syiah Kuala for the support.

\section{Conflict of interest}

The authors declare that they have no competing interests.

\section{Funding}

This study received no external funding.

\section{Underlying data}

All data underlying the results are available as part of the article and no additional source data are required.

\section{Supplementary Material}

PRISMA checklist is available from: https://doi.org/10.6084/m9.figshare.14235287.

\section{How to cite}

Fajar JK, Ilmawan M, Mamada SS, et al. Global prevalence of persistent neuromuscular symptoms and the possible pathomechanisms in post SARS-CoV-2 infection individuals: A systematic review and meta-analysis. Narra J 2021; 1 (3): e48. http://doi.org/ 10.52225/narra.v1i3.48.

\section{References}

1. Johns Hopskins University. COVID-19 dashboard by the center for systems science and engineering (CSSE) https://coronavirusjhuedu/maphtml (Accessed: April 20, 2021).

2. Badiani AA, Patel JA, Ziolkowski K, et al. Pfizer: The miracle vaccine for COVID-19? Public Health Pract 2020; 1:100061-100061.

3. Iserson KV. SARS-CoV-2 (COVID-19) vaccine development and production: an ethical way forward. Camb Q Healthc Ethics 2021; 30(1):59-68.

4. Peiris M, Leung GM. What can we expect from first-generation COVID-19 vaccines? Lancet 2020; 396(10261):14671469.

5. Giannakeas V, Bhatia D, Warkentin MT, et al. Estimating the maximum capacity of COVID-19 cases manageable per day given a health care system's constrained resources. Ann Intern Med 2020; 173(5):407-410.

6. Greene CJ, Burleson SL, Crosby JC, et al. Coronavirus disease 2019: International public health considerations. J Am Coll Emerg Physician Open 2020; 1(2):70-77.

7. Lew HL, Oh-Park M, Cifu DX. The war on COVID-19 pandemic: Role of rehabilitation professionals and hospitals. American journal of physical medicine \& rehabilitation 2020. Am J Phys Med Rehabil: doi: 10.1097/PHM.0000000000001460 (In press).

8. Fahriani M, Anwar S, Yufika A, et al. Disruption of childhood vaccination during the COVID-19 pandemic in Indonesia. Narra J 2021; 1(1):e7.

9. Bonal X, González S. The impact of lockdown on the learning gap: family and school divisions in times of crisis. Int Rev Educ 2020; 66(5):635-655. 
10. Pokhrel S, Chhetri R. A literature review on impact of COVID-19 pandemic on teaching and learning. High Educ Future 2021; 8(1):133-141.

11. Martin A, Markhvida M, Hallegatte S, et al. Socio-economic impacts of COVID-19 on household consumption and poverty. Econ Disasters Climate Change 2020; 4(3):453-479.

12. Mofijur M, Fattah IMR, Alam MA, et al. Impact of COVID-19 on the social, economic, environmental and energy domains: Lessons learnt from a global pandemic. Sustain Prod Consum 2021; 26:343-359.

13. Nicola M, Alsafi Z, Sohrabi C, et al. The socio-economic implications of the coronavirus and COVID-19 pandemic: a review. Int J Surg. 2020;78: 185-193.

14. Kanitkar T. The COVID-19 lockdown in India: Impacts on the economy and the power sector. Global Transitions 2020; 2:150-156.

15. Mudatsir M, Yufika A, Nainu F, et al. Antiviral Activity of ivermectin against SARS-CoV-2: an old-fashioned dog with a new trick—a literature review. Scientia Pharmaceutica 2020; 88(3):36.

16. Frediansyah A, Tiwari R, Sharun K, et al. Antivirals for COVID-19: a critical review. Clin Epidemiol Glob Health 2021:9:90-98.

17. Frediansyah A, Nainu F, Dhama K, et al. Remdesivir and its antiviral activity against COVID-19: A systematic review. Clin Epidemiol Glob Health 2021;9:123-127.

18. Li L, Zhang W, Hu Y, et al. Effect of convalescent plasma therapy on time to clinical improvement in patients with severe and life-threatening COVID-19: a randomized clinical trial. JAMA 2020; 324(5):460-470.

19. Simonovich VA, Burgos Pratx LD, Scibona $P$, et al. A randomized trial of convalescent plasma in covid-19 severe pneumonia. New Eng J Med 2020; 384(7):619-629.

20. Zhang $Y$, Geng X, Tan Y, et al. New understanding of the damage of SARS-CoV-2 infection outside the respiratory system. Biomed Pharmacother 2020:110195.

21. Robba C, Battaglini D, Pelosi P, et al. Multiple organ dysfunction in SARS-CoV-2: MODS-CoV-2. Expert Rev Respir Med 2020; 14(9):865-868.

22. Dhama K, Patel SK, Pathak M, et al. An update on SARS-CoV-2/COVID-19 with particular reference to its clinical pathology, pathogenesis, immunopathology and mitigation strategies. Travel Med Infect Dis 2020; 37:101755.

23. Rodriguez-Morales AJ, Cardona-Ospina JA, Gutierrez-Ocampo E, et al. Clinical, laboratory and imaging features of COVID-19: A systematic review and meta-analysis. Travel Med Infect Dis 2020; 34:101623.

24. Harapan H, Itoh N, Yufika A, et al. Coronavirus disease 2019 (COVID-19): A literature review. J Infect Public Health 2020; 13(5):667-673.

25. Long B, Brady WJ, Koyfman A, et al. Cardiovascular complications in COVID -19. Am J Emerg Med 2020;38(7):15041507

26. Dhakal BP, Sweitzer NK, Indik JH, et al. SARS-CoV-2 infection and cardiovascular disease: COVID-19 heart. Heart Lung Circ 2020; 29(7): 973-987.

27. Kraemer MUG, Yang CH, Gutierrez B, et al. The effect of human mobility and control measures on the COVID-19 epidemic in China. Science 2020; 368(6490):493-497.

28. Baig AM, Khaleeq A, Ali U, et al. Evidence of the COVID-19 virus targeting the CNS: tissue distribution, host-virus interaction, and proposed neurotropic mechanisms. ACS Chem Neurosci 2020; 11(7):995-998.

29. Song E, Chow RD, Jiang R, et al. Immunologically distinct responses occur in the CNS of COVID-19 patients. bioRxiv 2020: 2020.09.11.293464.

30. Mutiawati E, Fahriani M, Mamada SS, et al. Anosmia and dysgeusia in SARS-CoV-2 infection: incidence and effects on COVID-19 severity and mortality, and the possible pathobiology mechanisms-a systematic review and metaanalysis. F1000Research 2021; 10(40):40.

31. Syahrul S, Maliga HA, Ilmawan M, et al. Hemorrhagic and ischemic stroke in patients with coronavirus disease 2019: incidence, risk factors, and pathogenesis-a systematic review and meta-analysis. F1000Research 2021; 10(34):34.

32. Patel SK, Singh R, Rana J, et al. The kidney and COVID-19 patients - Important considerations. Travel Med Infect Dis 2020; 37:101831.

33. Townsend L, Dyer AH, Jones $\mathrm{K}$, et al. Persistent fatigue following SARS-CoV-2 infection is common and independent of severity of initial infection. PLOS ONE 2020; 15(11):e0240784.

34. Miyazato Y, Morioka S, Tsuzuki S, et al. Prolonged and late-onset symptoms of coronavirus disease 2019. Open Forum Infec Dis 2020; 7(11): ofaa507. 
35. Caronna E, Ballvé A, Llauradó A, et al. Headache: A striking prodromal and persistent symptom, predictive of COVID-19 clinical evolution. Cephalalgia 2020; 40(13):1410-1421.

36. Hopkins C, Surda P, Vaira LA, et al. Six month follow-up of self-reported loss of smell during the COVID-19 pandemic. Rhinology 2021; 59(1):26-31.

37. Davis HE, Assaf GS, McCorkell L, et al. Characterizing Long COVID in an International Cohort: 7 Months of Symptoms and Their Impact. medRxiv 2020:2020.2012.2024.20248802.

38. Junhua M, Qi Z, Xue G, et al. Analysis of psychological and sleep state of medical stuff with novel coronavirus pneumonia. Herald Med 2020; 39(3):345-349.

39. Fahriani M, IImawan M, Fajar JK, et al. Persistence of long COVID symptoms in COVID-19 survivors worldwide and its potential pathogenesis-A systematic review and meta-analysis. Narra J 2021; 1(2):e36.

40. Goertz YMJ, Van Herck M, Delbressine JM, et al. Persistent symptoms 3 months after a SARS-CoV-2 infection: the post-COVID-19 syndrome? ERJ Open Res 2020; 6(4)

41. Moher D, Liberati A, Tetzlaff J, et al. Preferred reporting items for systematic reviews and meta-analyses: The PRISMA statement. Plos Med 2009; 6(7):e1000097.

42. World Health Organization. Clinical management of COVID-19: interim guidance, 27 May 2020. World Health Organization; 2020.

43. China National Health Commission. Chinese clinical guidance for COVID-19 pneumonia diagnosis and treatment. 2020.

44. Mutiawati E, Syahrul S, Fahriani M, et al. Global prevalence and pathogenesis of headache in COVID-19: A systematic review and meta-analysis. F1000Research 2020; 9(1316):1316.

45. Stang A. Critical evaluation of the Newcastle-Ottawa scale for the assessment of the quality of nonrandomized studies in meta-analyses. Eur J Epidemiol 2010; 25(9):603-605.

46. Cochrane T. Review Manager (RevMan) 5.3. Copenhagen: The Nordic Cochrane Centre 2008; 373.

47. Carfi A, Bernabei R, Landi F, et al. Persistent symptoms in patients after acute COVID-19. JAMA 2020; 324(6):603605.

48. Cellai M, O'Keefe JB. Characterization of prolonged COVID-19 Symptoms in an outpatient telemedicine clinic. Open Forum Infect Dis 2020; 7(10):ofaa420.

49. Daher A, Balfanz P, Cornelissen C, et al. Follow up of patients with severe coronavirus disease 2019 (COVID-19): Pulmonary and extrapulmonary disease sequelae. Respir Med 2020; 174:106197.

50. Huang C, Huang L, Wang Y, et al. 6-month consequences of COVID-19 in patients discharged from hospital: a cohort study. Lancet 2021; 397(10270):220-232.

51. Liang L, Yang B, Jiang N, et al. Three-month Follow-up Study of Survivors of Coronavirus Disease 2019 after Discharge. J Korean Med Sci 2020; 35(47):e418.

52. Lu Y, Li X, Geng D, et al. Cerebral micro-structural changes in COVID-19 patients - An MRI-based 3-month followup study. EClinicalMedicine 2020; 25:100484.

53. Miyazato Y, Morioka S, Tsuzuki S, et al. Prolonged and late-onset symptoms of coronavirus disease 2019. Open Forum Infect Dis 2020; 7(11):ofaa507.

54. Sami R, Soltaninejad F, Amra B, et al. A one-year hospital-based prospective COVID-19 open-cohort in the Eastern Mediterranean region: The Khorshid COVID Cohort (KCC) study. PLoS One 2020; 15(11):e0241537.

55. Wang $\mathrm{X}, \mathrm{Xu} \mathrm{H}$, Jiang $\mathrm{H}$, et al. Clinical features and outcomes of discharged coronavirus disease 2019 patients: a prospective cohort study. QJM 2020; 113(9):657-665.

56. Yan N, Wang W, Gao Y, et al. Medium Term follow-up of 337 patients with coronavirus disease 2019 (COVID-19) in a fangcang shelter hospital in wuhan, china. Front Med (Lausanne) 2020; 7:373.

57. Zhao YM, Shang YM, Song WB, et al. Follow-up study of the pulmonary function and related physiological characteristics of COVID-19 survivors three months after recovery. EClinicalMedicine 2020; 25:100463.

58. Xiong Q, Xu M, Li J, et al. Clinical sequelae of COVID-19 survivors in Wuhan, China: a single-centre longitudinal study. Clin Microbiol Infect 2021; 27(1):89-95.

59. Li Q, Zheng XS, Shen XR, et al. Prolonged shedding of severe acute respiratory syndrome coronavirus 2 in patients with COVID-19. Emerg Microbes Infect 2020; 9(1):2571-2577.

60. Yan CH, Prajapati DP, Ritter ML, et al. Persistent smell loss following undetectable SARS-CoV-2. Otolaryngol Head Neck Surg 2020; 163(5):923-925. 
61. Colson P, Rolain JM, Raoult D. Chloroquine for the 2019 novel coronavirus SARS-CoV-2. Int J Antimicrob Agents 2020;55(3):105923.

62. Wang $\mathrm{M}$, Cao $\mathrm{R}$, Zhang $\mathrm{L}$, et al. Remdesivir and chloroquine effectively inhibit the recently emerged novel coronavirus (2019-nCoV) in vitro. Cell Research 2020; 30(3):269-271.

63. Helms J, Kremer S, Merdji H, et al. Neurologic features in severe SARS-CoV-2 Infection. New Engl J Med 2020; 382(23):2268-2270.

64. Tenforde MW, Kim SS, Lindsell C], et al. Symptom duration and risk factors for delayed return to usual health among outpatients with COVID-19 in a multistate health care systems network-United States, March-June 2020. Morbidity and Mortality Weekly Report 2020; 69(30):993.

65. Moriguchi T, Harii N, Goto J, et al. A first case of meningitis/encephalitis associated with SARS-Coronavirus-2. Int J Infect Dis 2020; 94:55-58.

66. Paterson RW, Brown RL, Benjamin L, et al. The emerging spectrum of COVID-19 neurology: clinical, radiological and laboratory findings. Brain 2020; 143(10):3104-3120.

67. Bhatia R, Pedapati R, Komakula S, et al. Stroke in coronavirus disease 2019: a systematic review. J Stroke 2020; 22(3):324-335.

68. Toscano G, Palmerini F, Ravaglia S, et al. Guillain-Barré Syndrome Associated with SARS-CoV-2. New Engl J Med 2020; 382(26):2574-2576.

69. Miller C, O'Sullivan J, Jeffrey J, et al. Brachial Plexus neuropathies during the COVID-19 pandemic: a retrospective case series of 15 patients in critical care. Phys Ther 2021; 101(1):pzaa191.

70. Miller C, O'Sullivan J, Jeffrey J, et al. Brachial plexus neuropathies during the COVID-19 pandemic: a retrospective case series of 15 patients in critical care. Phys Ther 2021; 101(1).

71. Sánchez-Soblechero A, García CA, Sáez Ansotegui A, et al. Upper trunk brachial plexopathy as a consequence of prone positioning due to SARS-CoV-2 acute respiratory distress syndrome. Muscle \& Nerve 2020; 62(5):E76-E78.

72. Restivo DA, Centonze D, Alesina A, et al. Myasthenia gravis associated with SARS-CoV-2 infection. Ann Internal Med 2020; 173(12):1027-1028.

73. Revzin MV, Raza S, Warshawsky R, et al. Multisystem Imaging manifestations of COVID-19, Part 1: Viral pathogenesis and pulmonary and vascular system complications. RadioGraphics 2020; 40(6):1574-1599.

74. Revzin MV, Raza S, Srivastava NC, et al. Multisystem imaging manifestations of COVID-19, Part 2: From cardiac complications to pediatric manifestations. RadioGraphics 2020; 40(7):1866-1892.

75. Wiersinga WJ, Rhodes A, Cheng AC, et al. Pathophysiology, transmission, diagnosis, and treatment of coronavirus disease 2019 (COVID-19): A Review. JAMA 2020; 324(8):782-793.

76. Koralnik IJ, Tyler KL. COVID-19: A Global threat to the nervous system. Ann Neurol 2020; 88(1):1-11.

77. Kandemirli SG, Altundag A, Yildirim D, et al. Olfactory Bulb MRI and paranasal sinus CT findings in persistent covid19 anosmia. Academic Radiology 2021; 28(1):28-35.

78. Mesci P, Macia A, Saleh A, et al. Sofosbuvir protects human brain organoids against SARS-CoV-2. bioRxiv 2020:2020.2005.2030.125856.

79. Song E, Zhang C, Israelow B, et al. Neuroinvasion of SARS-CoV-2 in human and mouse brain. bioRxiv 2020:2020.2006.2025.169946.

80. Manganotti P, Bellavita G, D'Acunto L, et al. Clinical neurophysiology and cerebrospinal liquor analysis to detect Guillain-Barré syndrome and polyneuritis cranialis in COVID-19 patients: A case series. Journal of Medical Virology 2021; 93(2):766-774.

81. Chen JS, Alfajaro MM, Chow RD, et al. Nonsteroidal anti-inflammatory drugs dampen the cytokine and antibody response to SARS-CoV-2 Infection. J Virology 2021; 95(7):e00014-00021.

82. Day M. Covid-19: ibuprofen should not be used for managing symptoms, say doctors and scientists. BMJ 2020; 368:m1086.

83. Baig AM, Khaleeq A, Ali U, et al. Evidence of the COVID-19 virus targeting the CNS: tissue distribution, host-virus interaction, and proposed neurotropic mechanisms. ACS Chem Neurosci 2020; 11(7):995-998.

84. Huang J, Zheng M, Tang X, et al. Potential of SARS-CoV-2 to cause cns infection: biologic fundamental and clinical experience. Front Neurol 2020; 11:659.

85. Xu J, Lazartigues E. Expression of ACE2 in human neurons supports the neuro-invasive potential of COVID-19 virus. Cell Mol Neurobiol 2020:1-5. 
Fajar et al. Narra J 2021; 1 (3): e48 - http://doi.org/10.52225/narra.v1i3.48

86. Paliwal VK, Garg RK, Gupta A, et al. Neuromuscular presentations in patients with COVID-19. Neurol Sci 2020; 41(11):3039-3056.

87. Rodríguez Cruz PM, Cossins J, Beeson D, et al. The neuromuscular junction in health and disease: molecular mechanisms governing synaptic formation and homeostasis. Front Mol Neurosci 2020; 13(226).

88. Glass CK, Saijo K, Winner B, et al. Mechanisms underlying inflammation in neurodegeneration. Cell 2010; 140(6):918-934.

89. Chhetri S, Khamis F, Pandak N, et al. A fatal case of COVID-19 due to metabolic acidosis following dysregulate inflammatory response (cytokine storm). IDCases 2020; 21:e00829.

90. Goadsby PJ, Holland PR, Martins-Oliveira M, et al. Pathophysiology of Migraine: A Disorder of Sensory Processing. Physiological Reviews 2017; 97(2):553-622.

91. Bolay H, Gül A, Baykan B. COVID-19 is a real headache! Headache 2020; 60(7):1415-1421.

92. Mutiawati E, Syahrul S, Fahriani M, et al. Global prevalence and pathogenesis of headache in COVID-19: A systematic review and meta-analysis. F1000Research 2021; 9:1316.

93. Mutiawati E, Fahriani M, Mamada S, et al. Anosmia and dysgeusia in SARS-CoV-2 infection: incidence and effects on COVID-19 severity and mortality, and the possible pathobiology mechanisms - a systematic review and metaanalysis. F1000Research 2021; 10:40.

94. Cazzolla AP, Lovero R, Lo Muzio L, et al. Taste and smell disorders in COVID-19 patients: role of interleukin-6. ACS Chem Neurosci 2020; 11(17):2774-2781.

95. Bilinska K, Jakubowska P, Von Bartheld CS, et al. Expression of the SARS-CoV-2 entry proteins, ACE2 and TMPRSS2, in cells of the olfactory epithelium: identification of cell types and trends with age. ACS Chem Neurosci 2020; 11(11):1555-1562.

96. Bryche B, St Albin A, Murri S, et al. Massive transient damage of the olfactory epithelium associated with infection of sustentacular cells by SARS-CoV-2 in golden Syrian hamsters. Brain Behav Immun 2020; 89:579-586.

97. Torabi A, Mohammadbagheri E, Akbari Dilmaghani N, et al. Proinflammatory cytokines in the olfactory mucosa result in covid-19 induced anosmia. ACS Chem Neurosci 2020; 11(13):1909-1913.

98. Chandra A, Chakraborty U, Pal J, et al. Silent hypoxia: a frequently overlooked clinical entity in patients with COVID19. BMJ Case Rep 2020; 13(9).

99. Biniecka M, Canavan M, McGarry T, et al. Dysregulated bioenergetics: a key regulator of joint inflammation. Ann Rheum Dis 2016; 75(12):2192-2200.

100. Kim S, Hwang J, Xuan J, et al. Global Metabolite profiling of synovial fluid for the specific diagnosis of rheumatoid arthritis from other inflammatory arthritis. PLOS ONE 2014; 9(6):e97501.

101. McGarry T, Biniecka M, Veale DJ, et al. Hypoxia, oxidative stress and inflammation. Free Radic Biol Med 2018; 125:15-24.

102. Boyas S, Guével A. Neuromuscular fatigue in healthy muscle: underlying factors and adaptation mechanisms. Ann Phys Rehabil Med 2011; 54(2):88-108.

103. Littlewood-Evans A, Sarret S, Apfel V, et al. GPR91 senses extracellular succinate released from inflammatory macrophages and exacerbates rheumatoid arthritis. J Exp Med 2016; 213(9):1655-1662.

104. Shime H, Yabu M, Akazawa T, et al. Tumor-secreted lactic acid promotes IL-23/IL-17 proinflammatory pathway. J Immunol 2008; 180(11):7175-7183.

105. Hojman P, Brolin C, Nørgaard-Christensen N, et al. IL-6 release from muscles during exercise is stimulated by lactate-dependent protease activity. Am J Physiol Endocrinol Metab 2019; 316(5):E940-e947.

106. Tan L, Wang Q, Zhang D, et al. Lymphopenia predicts disease severity of COVID-19: a descriptive and predictive study. Signal Transduct Target Ther 2020; 5(1):33.

107. Wan JJ, Qin Z, Wang PY, et al. Muscle fatigue: general understanding and treatment. Exp Mol Med 2017; 49(10):e384.

108. Chernyak BV, Popova EN, Prikhodko AS, et al. COVID-19 and Oxidative Stress. Biochemistry (Mosc) 2020; 85(12):1543-1553.

109. Huang C, Wang Y, Li X, et al. Clinical features of patients infected with 2019 novel coronavirus in Wuhan, China. Lancet 2020; 395(10223):497-506.

110. Kaelin WG, Jr., Ratcliffe PJ. Oxygen sensing by metazoans: the central role of the HIF hydroxylase pathway. Mol Cell 2008; 30(4):393-402. 
Fajar et al. Narra J 2021; 1 (3): e48 - http://doi.org/10.52225/narra.v1i3.48

111. Imtiyaz HZ, Simon MC. Hypoxia-inducible factors as essential regulators of inflammation. Curr Top Microbiol Immunol 2010; 345:105-120.

112. Jung $Y$, Isaacs JS, Lee $S$, et al. Hypoxia-inducible factor induction by tumour necrosis factor in normoxic cells requires receptor-interacting protein-dependent nuclear factor kappa B activation. Biochem J 2003; 370(Pt 3):1011-1017.

113. Jung YJ, Isaacs JS, Lee S, et al. IL-1beta-mediated up-regulation of HIF-1alpha via an NFkappaB/COX-2 pathway identifies HIF-1 as a critical link between inflammation and oncogenesis. Faseb J 2003; 17(14):2115-2117.

114. Zhou J, Schmid T, Brüne B. Tumor necrosis factor-alpha causes accumulation of a ubiquitinated form of hypoxia inducible factor-1alpha through a nuclear factor-kappaB-dependent pathway. Mol Biol Cell 2003; 14(6):2216-2225.

115. Chung CP, Titova D, Oeser A, et al. Oxidative stress in fibromyalgia and its relationship to symptoms. Clin Rheumatol 2009; 28(4):435-438.

116. Kennedy G, Spence VA, McLaren M, et al. Oxidative stress levels are raised in chronic fatigue syndrome and are associated with clinical symptoms. Free Radic Biol Med 2005; 39(5):584-589. 